\title{
A TERRITORIALIDADE SOCIAL NA DIVISA IN- TERNACIONAL BRASIL-BOLIVIA, NO SUDOES- TE DE MATO GROSSO: UM ESTUDO SOBRE A FRONTEIRA E OS SUJEITOS FRONTEIRIÇOS
}

\section{Jucineth Glória do Espírito Santo Carvalho*}

Resumo: Apresenta-se, neste texto, uma discussão acerca da territorialidade social construída na fronteira Brasil-Bolívia, na porção sudoeste do Estado de Mato Grosso. Trata-se de uma pesquisa ainda em curso, que objetiva tecer uma análise sociológica e discutir a questão da territorialidade social construída pelos sujeitos fronteiriços na região delimitada, composta por trabalhadores rurais, pequenos produtores, fazendeiros e os povos tradicionais, mestiços, denominados "Chiquitanos". A região de estudo denomina-se Ponta do Aterro, engloba ainda parte de suas cercanias, localiza-se no município de Vila Bela da Santíssima Trindade, divisa com os municípios de Pontes e Lacerda, Porto Espiridião e, dentro da Amazônia legal. O recorte temporal do estudo abrange o período de 1940-2012. Os resultados preliminares da investigação apontam que a região se configura num espaço de confrontos e disputas, de enfrentamentos nos dilemas cotidianos, que se fazem presentes nas relações sociais e nos modos de ser e viver daqueles sujeitos. Com base nos estudos da Teoria Social e do leque de suas possibilidades de análise, utilizaram-se os recursos metodológicos oferecidos pela História Oral, memória, histórias de vida e suas fontes, além do levantamento documental. Intenta-se desvendar, na perspectiva dos habitantes locais, o "sentido e a fluidez" dos limites da fronteira dos Estados-Nação Brasil e Bolívia. A faixa de fronteira Brasil-Bolívia na região estudada recorrentemente constitui-se em espaços marginalizados pelo discurso político, que insiste em deixá-las sob a penumbra da ilicitude.

Palavras-chave: Conflitos. Sociedade. Fronteiriços.

\begin{abstract}
This paper presents a discussion about the social territoriality issues built on the border Brazil-Bolivia, in the southwest portion of the state of Mato Grosso. This research is still in progress, aiming to develop a sociological analysis and discuss the issue of social territoriality built by border residents in the defined area, who are rural workers, small producers, farmers and traditional people, mestizos, called "Chiquitanos". The study area is called the Landfill Point, but also includes part of its surroundings. It is located at the city of Vila Bela da Santíssima Trindade, bordering the municipalities of Pontes e Lacerda, Porto Espiridião and within the legal Amazon. The time frame of the study covers the period 1940-2012. Preliminary research results indicate that the region set up an area of confrontation and disputes, conflicts in everyday dilemmas are present in social relationships and in those residents' ways of being and living. Based on the studies of Social Theory, and considering the range of their possibilities of analysis, it uses the methodological features offered by Oral History, memory, life stories and their sources, but also the documentary survey. It intends to unveil, from the perspective of locals, the "sense and fluidity" of the limits of the border States Nation between Brazil and Bolivia. The Brazil-Bolivia border strip in the studied region is recurrently marginalized by the political discourse, which insists on leaving them under the shadow of illicitness.
\end{abstract}

Key Words: Conflict. Society. Borders.

* Docente e Pesquisadora vinculada ao IFMT - Instituto Federal de Educação, Ciência e Tecnologia de Mato Grosso; Doutoranda do Programa de Pós-Graduação em Sociologia-UFSCar - Universidade Federal de São Carlos, na linha de pesquisa: Urbanização, ruralidades, desenvolvimento e sustentabilidade ambiental. Bolsista da Fundação de Amparo à Pesquisa de Mato Grosso - FAPEMAT. E-mail: jucineth.2013@gmail.com 
Escola Estadual 11 de Agosto $^{3}$, o comércio e também os serviços públicos disponíveis. O espaço fronteiriço

A região em estudo dista aproximadamente 680 km de Cuiabá, capital do Estado de Mato Grosso, rumo Oeste. Trata-se de uma área da faixa de fronteira ${ }^{1}$, localiza-se na intersecção dos limites físicos entre Brasil-Bolívia, inserida na Amazônia legal. Tomada como objeto investigativo, o local denomina-se Ponta do Aterro, bem como, parte de suas cercanias. Trata-se de um povoamento localizado no município de Vila Bela da Santíssima Trindade, que, por sua vez, limita-se com os municípios de Pontes e Lacerda e Porto Espiridião, no Sudoeste de Mato Grosso. Vale ressaltar que o município de Vila Bela da Santíssima Trindade foi a primeira capital de Mato Grosso, no período de 1752-1820, temporalidade inserida no contexto do Brasil-colônia.

A região da Ponta do Aterro e parte de suas cercanias compõem-se por treze comunidades, a saber: Santa Clara, Aparecida, São Miguel, Ponto Chique, Morrinhos, São Paulo, Santa Maria, Santa Lúcia, Cruzes, São Vicente, Santa Mônica, Fazenda São Marcos e Fazenda São Lucas, reunindo aproximadamente 180 famílias $^{2}$, grande parte formadas por migrantes originários de movimentos de ocupação da Amazônia Legal, descendentes de indígenas e povos de nacionalidade boliviana e ou mestiça, habitantes da fronteira, os "Chiquitanos".

Na região da Ponta do Aterro, a Comunidade mais estruturada é a Santa Clara, chamada de "Vila" pelos habitantes locais, com aproximadamente 100 casas. Na localidade funciona a Subprefeitura do município de Vila Bela da Santíssima Trindade, a Escola Municipal de Ensino Fundamental Ponta do Aterro/

\footnotetext{
${ }^{1}$ A Lei $n^{\circ}$ 6634, de 02 de maio de 1979, que dispõe sobre a faixa de fronteira, considera em seu artigo $1^{\circ}$ : É considerada área indispensável à Segurança Nacional a faixa interna de $150 \mathrm{Km}$ (cento e cinquenta quilômetros) de largura, paralela à linha divisória terrestre do território nacional, que será designada como Faixa de Fronteira.

${ }^{2}$ Dados levantados junto à Subprefeitura de Vila Bela da Santíssima Trindade, na Comunidade Santa Clara.
} investigado constitui-se por um misto de grandes propriedades rurais (as fazendas), minifúndios derivados de projetos de assentamentos rurais, a população habitante da "vila Santa Clara" e das demais comunidades mencionadas.

A escolha da área de estudo fundamentou-se em dois aspectos: 1 - localização geográfica e posição geopolítica, isto porque se entendeu a priori que se trata de uma região de fronteira física com a Bolívia e, portanto, o "lugar" da materialização do movimento das territorialidades e que este é permeado por relações de poder sobre o espaço, o que neste entendimento, muito poderá contribuir no sentido de desvelar o sentido da "fronteira" para a população local; 2 - levantamento da necessidade emergente de aprofundar a análise sobre a territorialidade social constituída na fronteira, avaliando-a nessa perspectiva como um extenso e instigante campo aberto a investigações e reinterpretações.

O trajeto metodológico pauta-se nos estudos construídos pela Teoria Social e no levantamento documental, associado às ferramentas oferecidas pela História Oral: memória, histórias de vida e suas fontes. Intenta-se desvendar, na perspectiva dos habitantes locais e dos conflitos instalados, o "sentido e a fluidez" dos limites da fronteira dos Estados-Nação Brasil e Bolívia.

A FRONTEIRA E OS FRONTEIRIÇOS: TERRITORIALIDADES E CONFLITOS

Discute-se nesta seara o sentido de "fronteira" no espaço pesquisado. A trajetória da análise sobre espacialidades contemporâneas nas áreas fronteiriças remete à compreensão dos diferentes sentidos e signi-

\footnotetext{
${ }^{3}$ Ambas as unidades escolares funcionam no mesmo prédio e atendem a aproximadamente 420 alunos.
} 
ficados contidos na designação da fronteira. Repensar as fronteiras pressupõe compreender a relação entre centro e periferia, público e privado, legal e ilegal.

A apropriação física do espaço na fronteira sudoeste de Mato Grosso inscreveu-se num canteiro de poder simbólico, político e econômico, cuja interface se dá com o "sentido" de apropriação por parte dos migrantes e que, ao mesmo tempo, colide com a presença de uma população de descendência indígena, os Chiquitanos. Originou-se daí uma questão latente: a identidade dos fronteiriços, quem são? Índios? Brasileiros? Bolivianos?

Portanto, à guisa de entendimento, é necessário considerar que, na região da fronteira em estudo, há uma discussão pautada no aspecto da etnicidade, o que envolve e, em certa medida, opõe aqueles que se consideram não índios aos que se consideram indígenas de origem chiquitana.

Para melhor situar a presença indígena na área investigada, tomamos por referência os estudos de Silva (2008), que, com base no mapa etno-histórico de Alfred Métraux, de 1948, conceitua que:

Chiquitano refere-se ao amálgama de inúmeras nações indígenas. Não são bolivianos ou estrangeiros no Brasil, estavam em solo nacional anteriormente à ocupação portuguesa. Portanto, antes da chegada dos portugueses, esses povos ocupavam as margens do rio Guaporé no Brasil, até as planícies bolivianas. O povo constituía-se num continuum e a fronteira geopolítica tratou de transformar em estrangeiros povos que viviam comprovadamente nessa região há muitos séculos, a divisão territorial transformou-se em dois países: O Brasil e a Bolívia.

No contexto geopolítico dessa região fronteiriça, ainda de acordo com os estudos de Silva (2008), a partir de 1768 os chiquitanos foram incorporados ao trabalho nas fazendas. No século XIX eram capturados para trabalhar na extração da borracha, nos seringais ou "gomales". Com relação ao trabalho, são considerados exímios trabalhadores em fazendas de criação de gado, uma habilidade herdada da convivência com os jesuítas, no período colonial brasileiro. Segundo a estudiosa acima citada, na fronteira sudoeste de MT com a Bolívia, que se estende por cerca de 500 quilômetros, há trinta e duas comunidades chiquitanas.

O conflito interétnico permeia as relações sociais estabelecidas na fronteira Brasil-Bolívia ora perscrutado, pois traz à tona a divergência entre: os grupos indígenas, os grandes proprietários rurais e os fazendeiros, no que se refere à posse e propriedade das terras. Inegavelmente, há muitos confrontos de interesses, fomentados, por um lado, pela possibilidade de demarcação da área e transformação desta em reserva indígena por parte do Estado brasileiro e, por outro, a expansão das possibilidades de exploração para produção de soja e instalação do agronegócio.

Num outro viés, vale destacar que a descendência chiquitana na fronteira também é carregada pela vertente do racismo e da discriminação, é comum a denominação pejorativa de "bugre" referindo-se a essa parcela da população fronteiriça. Sobre o significado do uso do termo bugre na faixa de fronteira, Silva (2008, p. 135) ensina que: "Bugre, naquele contexto, não queria dizer exatamente povo, mas uma espécie de gente, muito procurada para o trabalho, porém, pouco qualificada enquanto ser humano. Um exemplo brutal de etnocentrismo e do estranhamento".

É possível verificar a formação de grupos políticos de interesse regional na fronteira e porque não dizer, nas terras da fronteira, grupos estes que vão, ao longo do tempo e das relações, sendo reconhecidos e legitimados. Em contrapartida, também é possível observar nas falas e nas reações implícitas das comunidades investigadas, o "ocultamento da identidade chiquitana", que fortalece a confirmação da hipótese de que se trata de um conjunto de ações estratégicas de autoproteção.

$\mathrm{Na}$ região fronteiriça em estudo, há vários 
assentamentos regulamentados pelo $\mathrm{INCRA}^{4}$, os pequenos proprietários, em grande parte, os grupos descendentes de chiquitanos são assentados, fazem jus aos benefícios sociais, tais como: bolsa-família e aposentadoria rural. Mesmo com as suas pequenas propriedades, é prática comum os homens trabalharem como vaqueiros nas grandes fazendas de criação de gado, enquanto os demais membros da família se revezam em cultivos e cuidados com a propriedade e os trabalhos domésticos.

Nota-se, no contexto do trabalho do sujeito fronteiriço, uma intensa precarização das condições nas fazendas, entretanto, segundo alguns entrevistados, atualmente o trabalho escravo foi abolido, principalmente em decorrência de intensas e frequentes fiscalizações por parte da Justiça do Trabalho brasileira, a aplicação de multas trabalhistas e outras ações inibidoras de tal prática.

Quanto à prática da dominação e da violência, especialmente no que tange à posse e propriedade das terras, são marcas implícitas naquela paisagem, ocultadas sob a égide de uma suposta convivência social harmônica. Ainda assim, percebe-se o domínio e o centro de poder nos "fazendeiros criadores de gado" representados pelos grupos sociais proprietários de terras sobre as populações compostas por trabalhadores rurais, mestiços e chiquitanos.

No sentido de compreender melhor a questão, o primeiro grupo, comumente autointitulado de "desbravadores", dentre o rol de argumentos, se legitimam como elites políticas e econômicas locais e exercem o "controle" sobre os demais com base na exploração da força de trabalho, muitas vezes com total precarização das condições de trabalho e sobrevivência. Em última instância, o controle social é exercido pela definição de "quem vive ou quem morre", sendo comum ainda na região a ocorrência do extermínio de pessoas e famílias por assassinato. Isso decorre principalmente com o propósito de domínio da terra ou ${ }^{4}$ INCRA - Instituto Nacional de Colonização e Reforma Agrária, responsável pela regulamentação das terras destinadas à reforma agrária. do território.

Constata-se que, no exercício do controle social, a posse e propriedade da terra são a principal causa de conflitos que provocam as mais diversas formas de violência e intimidação por parte dos interessados, os jogos de interesse se colocando na linha de frente das questões, no choque das relações de poder estabelecidas.

No sentido da ocupação do espaço de investigação, ou seja, o espaço da fronteira sudoeste de MT, região que também está inserida no limite internacional entre Brasil e Bolívia, há que se fazer a leitura deste como um espaço de confrontos e disputas, que se fazem presentes nas relações sociais e nos modos de ser daqueles sujeitos.

Pode-se estabelecer, com base em Bourdieu (2002), uma crítica à "naturalização" das relações sociais de dominação, utilizando-se o conceito de habitus e sua propagação por meio de ações irrefletidas. Bourdieu viabiliza a percepção da dominação e desigualdade onde outros percebem harmonia e pacificação. $\mathrm{Na}$ análise social das sociedades centrais ou periféricas constata-se corriqueiramente a dominação simbólica sobre a ideologia de igualdade, o que origina uma imagem de consenso social e político, que, de certa forma, obscurece as relações de desigualdade.

A faixa de fronteira Brasil-Bolívia recorrentemente constitui-se em espaços marginalizados pelo discurso político, que insiste em deixá-las sob a penumbra da ilicitude, destacando-se de forma preconceituosa: o tráfico de drogas, a prostituição, o contrabando, roubos de veículos e outros crimes, o que confere às áreas de fronteira no Brasil um aspecto hostil e perigoso, transformadas pela imagem mitificada que se perpetua, não encontrando rival ou, não se oportunizando a construção da concepção do contraditório. São lugares de desordem? Ou locais onde o Estado não conseguiu impor sua ordem? Nessa perspectiva, a fronteira não pode e não deve ser analisada e menos ainda compreendida somente como o "lugar" 
de ilicitude e/ou da transgressão.

Trata-se de um exercício reflexivo frente à importância e necessidade de compreensão dos elementos institucionais e sociais na fronteira mencionada, bem como, suas formas intrínsecas de movimentação, ordenamento, interações e desdobramentos na reprodução de tal espacialidade, de caráter sociológico.

O Estado BRASILEIRO E A CONSTITUIÇÃO DA FRONTEIRA BRASIL-BOLÍVIA: UMA BREVE CONTEXTUALIZAÇÃO

Constatou-se, neste recorte de estudo, que, na atualidade, tal processo de configuração da fronteira no Sudoeste de Mato Grosso, na Amazônia legal pelo Estado brasileiro, decorreu de diferentes momentos da articulação capitalista, inserindo neste processo ainda mudanças estruturais e conjunturais acerca de desenvolvimento econômico e político, perpassando ainda pelas esferas do simbólico e cultural.

O conjunto de ações desencadeadas pelo Estado brasileiro e pelas forças políticas pode explicitar de maneira segura um quadro ou uma chave teórica que justifique a forma de ocupação e o modelo produtivo instituído na fronteira.

Nesse entendimento, todos os contextos que influenciaram a organização do espaço social na região de fronteira delimitada na pesquisa, relacionam-se, a priori, com a gênese da formação do Estado brasileiro. Neste exercício considerou-se adequado tomar por base a concepção de Estado formulada por Gramsci (1991, p.234), pois, conforme esse teórico, “o Estado deve ser interpretado como um complexo de atividades práticas e teóricas constituídas pelas esferas da sociedade política e da sociedade civil. Nesse caso, na sociedade política (Estado restrito) predominaria a coerção e na sociedade civil, o consenso".

Para entender melhor o processo de ocupação do Oeste brasileiro e também da região pesquisada, é necessário discorrer sobre a implementação do Mar- cha para o Oeste, que foi uma iniciativa do Estado brasileiro, tratada como uma política estatal de desenvolvimento do país, o movimento se efetivou na década de 40, caracterizado pelo desencadeamento de um intenso processo migratório, com o intuito de promover a "ocupação dos espaços vazios na Amazônia e no Oeste do País". Constatou-se a influência e o desdobramento de tais ações na formação dos espaços rurais e urbanos no contexto da fronteira citada, notadamente, a partir do mesmo período. Ou seja, a partir dessa década acima mencionada.

Desse modo, é possível pensar a "Marcha para o Oeste", assim como outros movimentos posteriores de "ocupação" das regiões de fronteira neste país, como consequência de processos dimensionalmente maiores e mais profundos quanto à ocupação do espaço, englobando para isso tanto a ordem posta no sistema colonial quanto posteriormente, à definição de uma política de Estado para o Brasil, pautada no domínio territorial e controle social.

Posteriormente à Marcha para Oeste, outros movimentos migratórios foram desencadeados com o aval do Estado como forma de dissipar as pressões sociais nos grandes centros, sob o pretexto de ocupar "espaços vazios" e de ampliação de oportunidades de elevação econômica e de qualidade de vida da população que se dispusesse a ocupar tais espaços.

A despeito desta análise, constatou-se que, na atualidade, tal processo de configuração da fronteira no Sudoeste de Mato Grosso, na Amazônia Legal pelo Estado brasileiro, decorreu de momentos da articulação capitalista, inserindo nesse processo, ainda, mudanças estruturais e conjunturais acerca de desenvolvimento econômico e político, perpassando, ainda, pelas esferas do simbólico e cultural.

A leitura de Gramsci acerca da "Ideologia da Hegemonia" (1998), trazida à luz do conjunto de ações desencadeadas pelo Estado brasileiro e pelas forças políticas, explicita um quadro ou uma chave teórica que justifica a forma de ocupação e o modelo produ- 
tivo instituído na fronteira. Estudos e levantamentos documentais realizados sobre o tema de pesquisa na região mostraram a interação entre as políticas de desenvolvimento do país e o contexto social e político, estabelecendo forças motrizes na configuração das espacialidades contemporâneas nas áreas fronteiriças.

A segunda metade do século XX no Brasil foi marcada por uma intensificação na formação espacial de cidades, modificações urbanas e reorganização dos espaços fronteiriços. Notadamente, a partir de 1964, com a instauração de um governo militar, foram muitas as transformações sociais e econômicas e que possibilitaram a consolidação do capitalismo no país. Nesse percurso, observou-se na leitura disponível que muitas são as contradições no processo histórico de acumulação capitalista, inserindo-se aqui a realidade mato-grossense.

$\mathrm{Na}$ fronteira Brasil-Bolívia, região selecionada para este estudo, sob determinado aspecto, observa-se a "naturalização da desigualdade social, típica de países periféricos como o Brasil", podendo-se, neste entendimento, traduzir como uma "suposta herança pré-moderna e personalista". Esta é decorrente de um forte movimento de modernização observado no Brasil e em alguns outros países da América Latina, atribuído, em grande parte, à transferência do modelo de produção industrial e, paulatinamente, à expressão de novas formas vida e quadros sociais, pautados em novas relações instituídas entre rural-urbano, uma vez que o País vivenciou uma intensa transformação de cunho socioeconômico a partir de meados do séc. $\mathrm{XX}$. Com isso altera-se de forma acentuada e acelerada a sua situação de agrário-exportador para urbano-industrial.

As ações modernizantes embutidas no "discurso político do crescimento econômico" propagada pelo Estado brasileiro a partir da segunda metade do Séc. XX, não explicam a extensão de tal modernidade à condição periférica de grande parte da sociedade brasileira ou as dramáticas contradições sociais ob- servadas no território brasileiro e talvez de maneira mais intensificada, nas vastas faixas de fronteira entre o Brasil e grande parte dos países latino-americanos, dentre os quais se destaca nesta investigação a fronteira Brasil-Bolívia, que só em Mato Grosso se estende por aproximadamente 500 quilômetros.

Essa modernização das sociedades periféricas teve lugar de destaque no debate internacional, o que estimulou o avanço das ciências sociais, atingindo o seu ápice no pós- guerra, acompanhando o esforço norte-americano na reorganização política do mundo livre.

Para discutir a territorialidade e o papel desempenhado pelo Estado na fronteira, propomos um exercício de compreensão do quadro da desigualdade social brasileira, o que neste entendimento, está inserido nas mazelas sociais dos países periféricos, assim como o Brasil, presentes na desigualdade e sua naturalização, na marginalização dos setores expressivos da população, na dificuldade de consolidação de uma ordem democrática e de mercado competitiva.

No intuito de compreender a grande complexidade da paisagem social na faixa de fronteira estudada, faz-se necessário desvelar e igualmente compreender o papel desempenhado pelo Estado brasileiro quanto à territorialidade e ações desencadeadas com o objetivo de estabelecer e/ou fortalecer a segurança nacional.

Para explorar tais sentidos, considerou-se pertinentes as seguintes indagações: Por que houve o desencadeamento de um intenso processo migratório rumo às regiões de fronteira? Em que medida tais movimentos se constituíram ideologicamente ou com o intuito de promover a ocupação dos espaços vazios na Amazônia e no Oeste do País? Quais são os desdobramentos destas ações na formação dos espaços rurais e urbanos no contexto da fronteira citada, notadamente, a partir da década de 40? Seria a fronteira o "lugar da exclusão" e do "vazio de direitos"? 
Nesse movimento interpretativo, somado à muitos embates teóricos e reflexões, pode-se entender que: "Todo Estado tem margem. O sujeito pode estar dentro ou fora dos critérios estabelecidos para estar INCLUÍDO ou EXCLUÍDO entre margem e centro". No que se concerne às relações inter-regionais, as regiões de fronteira, em especial o recorte em estudo, que engloba espaços que margeiam a Amazônia e Bolívia, constituem-se numa região geográfica periférica do país.

A desigualdade e a exclusão na territorialidade da fronteira, considerando o paradigma da modernidade, são discutidas como uma condição de exceção, que está relacionada diretamente à forma de organização societal. No contexto do sistema capitalista, considera-se como uma espécie de questão originada no desenvolvimento do modelo capitalista, portanto, justifica-se a necessidade de implementação de políticas sociais que minimizem tais excepcionalidades.

Na perspectiva de Marx (1969) e Foucault (2003), os grupos sociais que constituem a desigualdade e a exclusão estabelecem, cada um, uma hierarquia de pertença ao sistema, constituindo-se em dois "tipos ideais". A desigualdade pode ser caracterizada como um fenômeno socioeconômico, enquanto a exclusão está sedimentada como um fenômeno cultural e social, próprio da civilização. Afirma que: “em ambas as formas de hierarquização se pretende uma integração subordinada pelo trabalho".

As combinações complexas de tais sistemas de pertença dentro de uma hierarquia passam por um modelo de regulação social por parte do "Estado moderno" em sua gestão capitalista, ou seja, a desigualdade e a exclusão ao mesmo tempo em que, de certa forma, se constituem em forças motrizes do sistema, são devidamente monitoradas pela própria gestão no sentido de se "controlarem os extremismos"; nesse sentido, os mecanismos de controle ou de monitoração conforme denominamos, permitem sob determinada perspectiva, alguma emancipação dos grupos sociais pertencentes às situações de desigualdade e exclusão.

Com base na premissa de que a faixa de fronteira em estudo Brasil-Bolívia é também um lugar de exclusão e desigualdade e, ao mesmo tempo, um espaço inegável de materialização da ideologia de "segurança nacional sobre a territorialidade", são comuns diversos conflitos sociais cujas características são: etnização da força de trabalho, luta pela posse da terra, coexistência de diferentes nacionalidades e identidades étnicas, atuação de forças decorrentes do processo de globalização da cultura e descontextualização das culturas locais. Percebe-se, portanto, nessa espacialidade, a inserção de uma nova ordem mundial, globalizada e multicultural.

Neste quadro reflexivo, no contexto das contradições acerca do processo histórico de ocupação da Amazônia brasileira e, nesta, o recorte da porção sudoeste de MT, deve-se lançar um olhar crítico também sobre o processo de acesso à terra pública e/ou devoluta, bem como sobre a violência implícita na desfaçatez que é praticada contra nações indígenas, dentre as quais se destaca na área estudada a presença dos chiquitanos, os migrantes colonos e os posseiros. Há que se indagar o propósito das políticas públicas de cunho "desenvolvimentista", bem como suas consequências para a região em estudo.

Os espaços sociais constituem-se nas relações sociais. Na concepção de Michel Foucault (2003), explicitada em curso dado no Collège de France em 1976, tais espaços se configuram antes de tudo, em relações de poder, o que, por sua vez, é decorrente de diferentes mecanismos e estratégias deliberadas pelos indivíduos e pelas instituições. Nesse sentido, para o referido teórico, no exercício de compreensão dos espaços sociais há necessidade de se estabelecer uma prática analítica no intuito de desvelar esses mecanismos e estratégias.

A reflexão do autor leva à constatação de que o poder se institui com base em uma multiplicidade 
de fatores que perpassam pelas seguintes instituições: o poder disciplinar, o "biopoder", os discursos e as técnicas do direito, a obrigação legal e a soberania, entre outros. Trata-se de fatores que influenciarão diretamente as práticas de sujeição do indivíduo e/ou dos grupos sociais, uma forma de dominação contida na legitimidade do poder soberano, dos direitos legítimos e da obrigação "legal" de obediência.

Foucault questiona as relações de poder e práticas de sujeição nas sociedades ditas democráticas, discute as possibilidades de utilização do modelo estratégico da guerra no contexto das análises das relações de poder. No sentido de construir uma metodologia de compreensão das relações de poder (e não do poder em si), o autor elenca algumas precauções importantes para a compreensão da sua teoria, referindo-se a questões do método, nos quais destaca: a necessidade de compreender o poder nas extremidades, o que permite ir além das regras do direito (que para ele organiza e limita as relações de poder), sustentando que o poder tem sua essência na intencionalidade e objetivos, portanto, não estando centrado num indivíduo e/ou instituição.

$\mathrm{Na}$ análise de Foucault o poder se constitui numa rede de relações, num jogo de forças constante entre ambos os lados; as relações são dinâmicas, complexas e contraditórias. O Estado, nessa reflexão, não seria apenas e tão somente uma instituição centralizadora do poder, embora não se possa negar a influência de tal poder. Foucault salienta que o poder circula, transitando nos espaços de todo o corpo social.

Dessa forma, as redes de poder culminam com a formação de um sistema de saber. Assim, o poder exerce-se com base na formação e organização de um saber. Verifica-se, nesta esteira reflexiva, que as relações entre os indivíduos são relações de poder e não há um grupo social coeso, portanto não há poder estático ou centrado unicamente em algo ou alguém, embora, mesmo nas sociedades "ditas democráticas" como o Brasil, as instituições tenham um certo privi- légio ou talvez uma certa centralidade no exercício do poder em função do papel que desempenham no bojo das relações sociais, inclusive de vigilância, controle e garantia dos direitos civis fundamentais dos indivíduos.

Na tentativa de análise e compreensão do espaço social em estudo, inegavelmente, por se tratar de um espaço de fronteira, percebeu-se que, em diferentes momentos da história do Brasil, especialmente a partir da segunda metade do século XX, disseminaram-se a ideologia e as políticas públicas voltadas à manutenção da soberania nacional (do Estado) sobre o território, especificamente na faixa de fronteira do país. Se, por um lado, as políticas de desenvolvimento voltaram-se para garantir e fortalecer o poder estatal e suas estratégias de dominação em tais espaços, paradoxalmente, conforme se observa, a mesma faixa de fronteira em questão é carregada de contradições, práticas e ações que configuram e de certa forma, legitimam uma realidade pautada em diversas formas de violência e abandono.

E o movimento nas relações de poder? E os sujeitos fronteiriços? Partindo da premissa de que o sentido de poder consiste e coincide necessariamente com uma forma de saber e/ou com diversos saberes, pode-se pensar o sujeito fronteiriço e sua movimentação nos seus grupos sociais sob diferentes contextos, pode-se constatar que na área de estudo não há um grupo social coeso e as relações de poder se materializam, de um lado, entre o Estado e os indivíduos fronteiriços e, de outro, entre estes no seu próprio grupo social. Assim, forja-se certo "ordenamento" nos exercícios de poder, o que, por sua vez, legitima um "modo de ser e de viver".

Esses modos "de ser e viver" internalizados pelos grupos sociais que constituem o espaço social da fronteira, talvez, propositadamente propaguem o predomínio da rudeza nas relações entre os grupos sociais, concedendo à sua territorialidade um aspecto "perigoso", fortalecido inclusive no imaginário so- 
cial, reiterando, então, a ideia da faixa de fronteira como uma "terra sem lei" ou a "terra no fim do mun-

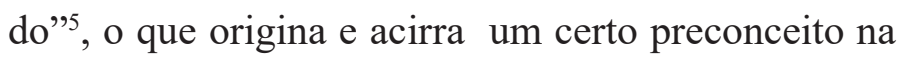
sentido centro-periferia do país.

Nesse enfoque entende-se que, sob o prisma de Foucault, nas relações entre o Estado e os grupos sociais fronteiriços e entre estes e seus pares, há um exercício de poder permanente, contido nas disputas pela posse e propriedade das extensões de terra; nos movimentos reivindicatórios por maior e melhor qualidade de vida (moradia, condições de sanitárias, assistência médica e transporte públicos); conflitos sociais de diversas ordens estão sempre em estado de "ebulição" na região.

Sobre o papel desempenhado pelo Estado na faixa de fronteira em estudo (Brasil-Bolívia, inserida na Amazônia), consegue-se perceber muitas contradições e, conforme a ocasião, o interesse e a conveniência, constatam-se a sua presença ou ausência.

A formulação de outra versão para a ideia de constituição da fronteira, num sentido não atrelado apenas à sua configuração física e/ou espacial, ou seja, extrapolando sua organização apenas em decorrência do papel do Estado e de suas ações nos moldes do desenvolvimento capitalista, mas, abarcando também, a sua forma particular de constituição, que se faz presente na mobilização de forças e na forma de inserção dos sujeitos sociais nesse espaço de estudo, implica, portanto, neste entendimento, olhar a fronteira fundamentando-se no movimento relacionado às relações sociais, reações, vivências, formas de ser e de se articular no "mundo fronteiriço".

\section{Algumas constatações}

Com relação ao controle social exercido pelo

5 Anotações retiradas de entrevistas preliminares com habitantes da faixa de fronteira em estudo.
Estado, entende-se que este recorrentemente transita paradoxalmente nas margens da legitimidade e ilegitimidade. Tomando por empréstimo uma referência de Agamben, constata-se que, no desempenho de seu papel, o Estado, sob a ótica da omissão ou da "negação de direitos" básicos aos fronteiriços, também constitui-se na fronteira Brasil-Bolívia como um Estado de Exceção, o que talvez possa justificar o aspecto de violência a abandono nessa paisagem, pois não frequentemente os direitos básicos são negados àquela população e, por vezes, a ausência e a ineficiência das instituições protetivas e básicas para a vida social implicam uma decisão deliberada sobre quem deve "viver ou morrer".

Pode-se, a título de exemplo, citar as condições precárias de higiene e saúde vivenciada pela população fronteiriça, especialmente as de menor poder aquisitivo que compõem a camada empobrecida, a saber: trabalhadores rurais, mestiços, chiquitanos e descendentes de negros (que vivem nas áreas de remanescentes de quilombos).

No recorte em estudo, ou seja, na fronteira Brasil-Bolívia, pode-se entender os conflitos como parte das estratégias de exercício de poder, tanto por parte do Estado quanto das camadas sociais entre si, delineando-se situações que envolvem diretamente o processo de "assujeitamento do outro", o que provoca as mais diversas formas de violência e intimidação, disfarçada, na maioria das vezes. Visualizam-se os jogos de interesse, que se colocam na linha de frente das questões, no choque das relações de poder estabelecidas.

Ainda quanto à constituição do poder do Estado brasileiro e de seus significados na organização do aspecto político da fronteira, outra observação importante está pautada na vida política local, elemento de fundamental importância para se analisar a existência ou inexistência dos sujeitos com base no contexto da inclusão e/ou exclusão do cenário político. Essa relação se destaca no sentido de pertencimento a uma 
comunidade e o seu reconhecimento enquanto ser político, elemento que habilita o indivíduo e/ou grupos sociais à condição de manutenção e garantias da vida individual e de acesso aos direitos na vida social e coletiva; no Estado de exceção a vida dos "seres humanos" reduz-se à sua dimensão biológica, apolítica e sem direitos.

Num confronto entre os referenciais teóricos arrolados e a realidade investigada na fronteira estudada, pode-se concluir, portanto, que, no universo das contradições fronteiriças, ao mesmo tempo em que o Estado brasileiro afirma o caráter universal do seu ordenamento jurídico, que define teoricamente "condições de igualdade" no acesso e proteção aos direitos dos sujeitos que compõem a sociedade de fronteira, nesse quadro, os seres que não se "constituem politicamente" estarão sempre à margem. Isso implica concretamente estar "dentro" e simultaneamente estar "fora", numa condição de sobrevivência pautada na exclusão e na precarização da vida cotidiana.

De uma forma bastante genérica, pode-se dizer que a organização social da "modernidade" se inseriu em um modelo capitalista de produção, forjando um modelo de constituição social à luz da perspectiva do pensamento europeu, que se desdobrou trazendo novas complexidades para a interpretação das relações sociais, de produção e trabalho na fronteira.

\section{REFERÊNCIAS BIBLIOGRÁFICAS}

AGAMBEN, G. Homo sacer - o poder soberano e a vida nua. Belo Horizonte: UFMG,. 2002. 2004.

. Estado de exceção. São Paulo: Boitempo,

ARENDT, Hannah. A condição humana. Tradução de Roberto Raposo. Rio de Janeiro: Forense Universitária, 2007.

BOURDIEU, Pierre. Razões práticas: sobre a teoria da ação. Campinas: Papirus, 1996.

O poder simbólico. $5^{\mathrm{a}}$ ed. Rio de Janeiro: Bertrand Bra- sil, 2002.

. Meditações pascalinas. Rio de Janeiro: Bertrand Brasil, 2007.

COUTINHO, C. N.; TEIXEIRA, A. de Paula. Ler Gramsci, entender a realidade. Rio de Janeiro: Civilização Brasileira, 2003.

DAS, Veena; POOLE, Deborah. (Orgs.). Anthropology in the margins of the State. Santa Fé. Oxford: School of American Research Press/ James Currey, 2004, 330 p. Resenha.

DREIFUS, Renê Armand. 1964: A conquista do Estado - ação política, poder e golpe de classe. Rio de Janeiro: Vozes, 1981.

DURKHEIM, E. As regras do método sociológico. $3^{\mathrm{a}}$ ed. São Paulo: Nacional, 1963.

FOUCAULT, M. Em defesa da sociedade. São Paulo: Martins Fontes, 2003.

. A Arqueologia do saber. Rio de Janeiro: Forense Universitária, 2005. . A ordem do discurso. São Paulo: Loyola, 2010. . As palavras e as coisas. São Paulo: Martins Fontes, 1981.

GIDDENS, Anthony. A constituição da sociedade. São Paulo: Martins Fontes, 2009.

GRAMSCI, A. Maquiavel, a politica e o Estado moderno. Trad. Luiz Mário Gazzaneo, $8^{\mathrm{a}}$ ed. Rio de Janeiro: Civilização Brasileira, 1991.

MARX, K. Ideologia alemã. Cidade do México: Fonte de Cultura, 1969.

OLIVEIRA, F. Crítica à razão dualista. O ornitorrinco. São Paulo: Boitempo, 2003.

SILVA, J.A.F. Identidades e conflitos na Fronteira. Poderes locais e os chiquitanos. Revista Memória Americana 16 (2), 2008, p. 119-148.

SOUZA, Jessé. A construção social da subcidadania. Belo Horizonte: UFMG, 2006.

SANTOS, Milton. Espaço e Método. São Paulo: Nobel, 1997.

SOJA, Edward W. Geografias pós-modernas: a reafirmação do espaço na teoria social crítica. Trad.: Vera Ribeiro. Revisão: Bertha Becker. Rio de Janeiro: Zahar, 1993. 